\title{
2D \& 3D Modelling Monumen Bersejarah Yogyakarta sebagai Media Edukasi Interaktif berbasis Virtual Reality
}

\author{
Eriya, Yesty Desca R.Putri \\ Program Studi Teknik Informatika \\ Politeknik Negeri Jakarta, \\ Depok, Indonesia \\ eriya@tik.pnj.ac.id, descafitaputri@gmail.com
}

\author{
Diterima: 1 April 2018. Disetujui: 20 April 2018. Dipublikasikan: Mei 2018
}

\begin{abstract}
Abstrak - Daerah Istimewa Yogyakarta merupakan daerah yang kaya akan sejarah. Untuk memperkenalkan beragam peninggalan sejarah yang ada di Kota Yogyakarta dan untuk meningkatkan minat terhadap edukasi sejarah maka diperlukan teknologi yang tepat yaitu dengan menggunakan teknologi Virtual Reality. Berdasarkan permasalahan tersebut, makalah ini bertujuan untuk membuat assetasset 3D dan 2D dengan menggunakan Adobe Ilustrator dan Blender dan merujuk pada monumen sejarah yang ada di DI Yogyakarta agar terlihat nyata. Aset 2D dan 3D ini akan digunakan sebagai konten dalam media edukasi interaktif monumen bersejarah DI Yogyakarta menggunakan teknologi Virtual Reality, sehingga pengguna dapat melihat monumen-monumen sejarah tersebut secara virtual yang akan memberikan pengalaman yang menarik bagi pengguna aplikasi.
\end{abstract}

Kata Kunci: multimedia, aset $2 D, 3 D$ modeling, media edukasi, virtual reality, Daerah Istimewa Yogyakarta.

\section{PENDAHULUAN}

Daerah Istimewa Yogyakarta (DIY) adalah sebuah daerah otonomi setingkat propinsi di Indonesia dengan lintasan sejarah yang cukup panjang. Kekayaan sejarah ini juga disertai oleh kekayaan pusaka sebagai bentuk peradaban yang tumbuh berkembang seiring dengan waktu. Pusaka ragawi berupa bangunan-bangunan bersejarah mulai dari Keraton Kerajaan, Tugu Yogyakarta, hingga Candi Prambanan, dll. Kesemuanya adalah sebuah modal yang sangat berharga dalam menghargai sejarah dan kehidupan berbudaya di Yogyakarta, terlebih di Indonesia [1].

Pada hakikatnya, sejarah merupakan ilmu yang menekankan pada pengembangan konsep serta struktur peristiwa. Namun kadang kala ilmu sejarah sering dianggap hanya sebagai urutan peristiwa. Hal tersebut terjadi karena metode pembelajaran yang digunakan dalam media edukasi sejarah terkesan monoton dan kurang bervariatif sehingga pemahaman mengenai hakikat dibalik peristiwa sejarah kurang dapat dipahami, serta menyebabkan kurangnya minat untuk mempelajari tentang ilmu sejarah di era modern.

Untuk meningkatkan pertumbuhan minat edukasi sejarah, maka perlu diupayakan sarana teknologi modern, salah satu cara nya yaitu dengan menggunakan teknologi virtual reality. Pada saat menggunakan teknologi virtual reality, disana akan banyak ditemukan objek-objek 3D baik itu berupa arsitektur bangunan ataupun beberapa objek yang ada dalam arsitektur tersebut dalam bentuk 3D [2]. Terlebih lagi, konten aplikasi dalam aplikasi virtual reality ini adalah animasi $2 \mathrm{D}$, dimana di dalamnya terdapak banyak objek 2D seperti karakter, background, dan lain-lain. Objek-objek 3D itu lah yang disebut sebagai asset 3D \& 2D.

Berdasarkan permasalahan tersebut, makalah ini bertujuan untuk membuat asset-asset 3D dan 2D untuk media edukasi interaktif menggunakan teknologi virtual reality dengan salah satu konten berupa animasi 2D berlingkup $360^{\circ}$ dengan aplikasi Blender dan Adobe Illustrator.

\section{TINJAUAN PUSTAKA}

\section{A. Grafis 2 Dimensi}

Grafik komputer 2D adalah sebuah generasi gambar digital (digital image) berbasis komputer, yang kebanyakan mengambil objek-objek dua dimensi (2D). Model grafik 2D merupakan kombinasi dari model geometri (juga disebut sebagai grafik vektor), gambar digital (raster graphics), fungsi matematika, dan sebagainya. Komponenkomponen ini dapat dimodifikasi dan dimanipulasi oleh transformasi geometri dua dimensi, seperti translasi, rotasi, dan dilatasi [3]. 


\section{B. Grafis 3 Dimensi}

Grafik 3D merupakan perkembangan dari grafik 2D. Di dalam grafika komputer, 3D merupakan bentuk grafik yang menggunakan representasi data geometri tiga dimensi. Suatu objek rangka $3 \mathrm{D}$ apabila disinari dari arah tertentu akan membentuk bayangan pada permukaan gambar. Proses pembuatan grafik komputer 3D dapat dibagi ke dalam tiga fase, yaitu 3D modelling yang mendeskripsikan bentuk dari sebuah objek, layout, dan animation yang mendeskripsikan gerakan dan tata letak sebuah objek, dan $3 \mathrm{D}$ rendering yang memproduksi image dari objek tersebut [3].

\section{Virtual Reality}

Virtual Reality (VR) atau realitas maya adalah teknologi yang membuat pengguna dapat berinteraksi dengan suatu lingkungan yang disimulasikan oleh komputer (computer-simulated environment), suatu lingkungan sebenarnya yang ditiru atau benar-benar suatu lingkungan yang hanya ada dalam imaginasi. Lingkungan virtual reality pada umumnya menyajikan pengalaman visual, yang ditampilkan pada sebuah layar komputer atau melalui sebuah penampil stereoskopik, tapi beberapa simulasi mengikutsertakan tambahan informasi hasil pengindraan, seperti suara melalui speaker atau headphone. Melalui headphone atau speaker, pendengar akan mendengar suara yang realistis [4].

\section{METODOLOGI}

Metode yang diterapkan pada pembuatan Asset Objek 2D \& 3D untuk Media Edukasi Interaktif adalah metode model Villamil-Molina. Villamil-Molina mengatakan bahwa pengembangan multimedia akan berhasil baik dengan membutuhkan perencanaan yang teliti, penguasaan teknologi multimedia yang baik, serta penguasaan manajemen produksi yang baik juga. Adapun tahapan metode model Villamil-Molina ini adalah seperti berikut [5]:

\section{A. Development}

Pada tahap ini yang dilakukan adalah menentukan konsep \& spesifikasi aset-aset 2D \& 3D yang akan dikembangkan berdasarkan ide, tujuan serta sasaran aplikasi virtual reality media edukasi sejarah mengenai 3 monumen di Yogyakarta. Konsep pembuatan aset 2D \& 3D dalam aplikasi VR ini adalah membuat aset-aset yang menarik bagi user dengan cara membuat desain background \& karakter yang dapat menyampaikan cerita \& pesan sejarah dalam animasi 2D, serta dengan membuat modelling 3D yang tampak nyata dengan perbandingan skala yang sesuai dengan monumen aslinya.

\section{B. Pre-production}

Pada tahap ini mulai melakukan pengumpulan bahan untuk proses pembuatan asetaset yang akan dikerjakan nantinya. Bahan-bahan tersebut, antara lain seperti riset foto \& lingkungan, serta sejarah asal mula \& perkembangan monumen yang dituang dalam bentuk storyboard \& skrip narasi. Setelah itu, dilakukan pengembangan konsep aset-aset secara rinci berdasarkan konten, storyboard, dan skrip narasi pada aplikasi VR media edukasi ini.

\section{Production}

Pada tahap ini, dilakukan pengembangan outline/garis besar aset-aset, desain antarmuka aplikasi, pengembangan grafis $2 \mathrm{D}$ dengan cara tracing \& coloring, serta pengembangan grafis 3D dengan cara modelling \& texturing sehingga menjadi sebuah aset utuh yang siap diuji \& dimasukkan pada animasi \& aplikasi virtual reality.

\section{Post-production}

Pada tahap ini, pembuatan aset-aset 2D \& 3D memasuki tahapan pengujian oleh animator \& programmer aplikasi. Aset-aset 2D \& 3D akan dievaluasi secara internal oleh tim dengan memperhatikan aspek-aspek a) desain aset, b) tujuan dan sasaran, c) konten, d) grafis, dan f) kesesuaian dengan storyboard.

\section{E. Delivery}

Tahap ini merupakan tahap akhir dari pembuatan aset 2D \& 3D. Aset-aset yang sudah di evaluasi oleh tim internal (animator \& programmer) lalu didistribusikan ke dalam animasi 2D dan aplikasi virtual reality.

\section{PERANCANGAN DAN REALISASI}

\section{A. Storyboard Aplikasi}

Storyboard aplikasi dibuat untuk memudahkan dalam proses pembuatan aset-aset pada bagian konten aplikasi. Gambar 1 berikut merupakan storyboard dari aplikasi media edukasi interaktif ini.
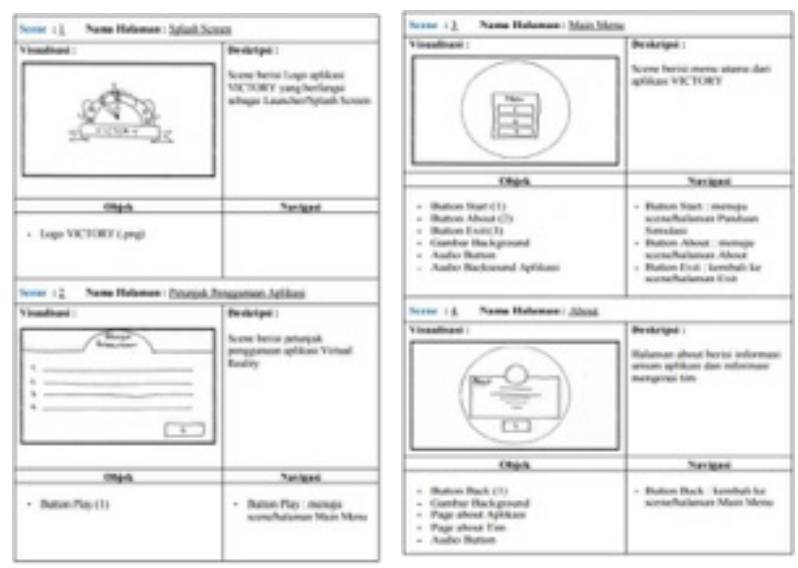


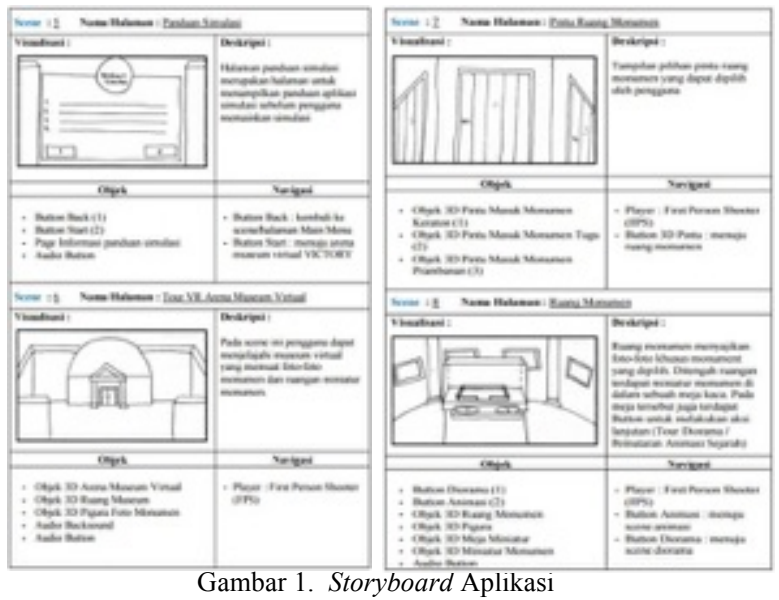

\section{B. Storyboard Animasi}

Selain storyboard aplikasi, juga terdapat storyboard animasi yang dibuat untuk memudahkan dalam proses pembuatan aset-aset animasi, seperti background dan karakter pada bagian cerita yang ditunjukkan pada Gambar 2.

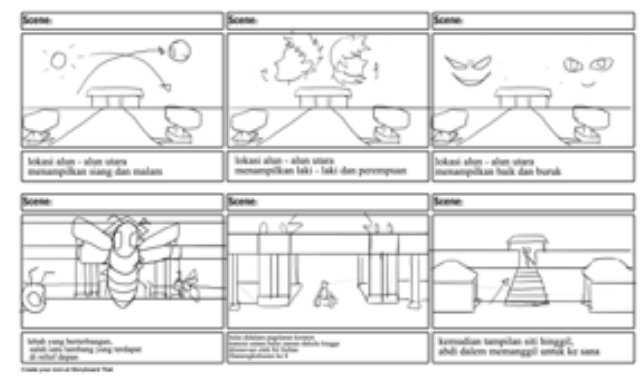

Gambar 2. Storyboard Animasi

\section{Desain Asset 2D}

Desain aset-aset 2D dibuat untuk memudahkan dalam pembuatan aset-aset 2D pada media edukasi interaktif berdasarkan storyboard aplikasi dan storyboard animasi yang sudah dijabarkan sebelumnya. Pada Tabel 1 merupakan desain aset-aset 2D beserta penjelasannya.

\section{TABEL 1. DESAIN ASSET 2D}

\begin{tabular}{|c|c|c|}
\hline No & Desain Asset & Deskripsi \\
\hline 1. & 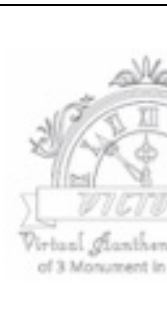 & $\begin{array}{l}\text { Nama Aset: Logo Aplikasi } \\
\text { Logo divisualisasikan } \\
\text { berupa jam dinding tempo } \\
\text { dahulu berbentuk setengah } \\
\text { lingkaran yang dibingka } \\
\text { dengan ukiran-ukiran } \\
\text { kaligrafi. Bagian dalam jam } \\
\text { terdapat angka-angka } \\
\text { romawi sebagai penunjuk } \\
\text { waktu dan jarum jam. }\end{array}$ \\
\hline 2. & & $\begin{array}{l}\text { Nama Aset: User Interface } \\
\text { Title: Main Menu } \\
\text { Tombol: } \\
\text { Start Journey, About, Exit }\end{array}$ \\
\hline
\end{tabular}

\begin{tabular}{|c|c|c|}
\hline 3. & $\left(\frac{6}{0}\right.$ & $\begin{array}{l}\text { Nama Aset: User Interface } \\
\text { Title: Instruction Page } \\
\text { Tombol: Start Journey, } \\
\text { Back }\end{array}$ \\
\hline 4. & 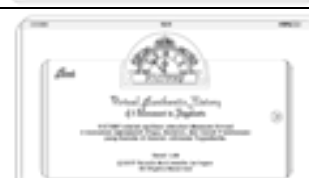 & $\begin{array}{l}\text { Nama Aset: User Interface } \\
\text { Title: About Application } \\
\text { Tombol: Slider Kanan, } \\
\text { Back }\end{array}$ \\
\hline 4. & 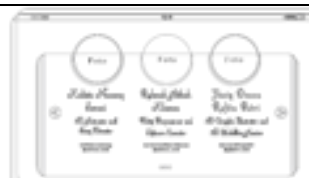 & $\begin{array}{l}\text { Nama Aset: User Interface } \\
\text { Title: About Developer } \\
\text { Tombol: Slider Kiri, Back }\end{array}$ \\
\hline 5. & $\sin y=2 n$ and it at? & $\begin{array}{l}\text { Nama Aset: User Interface } \\
\text { Title: Quit Condition } \\
\text { Tombol: Yes, No }\end{array}$ \\
\hline 6. & if 8 & $\begin{array}{l}\text { Nama Aset: Karakter } \\
\text { Title: 'Mbak Guide' } \\
\text { Deskripsi Aset: } \\
\text { Divisualisasikan sebagai } \\
\text { perempuan Jawa yang } \\
\text { berparas ayu, memakai } \\
\text { Kebaya berwarna biru dan } \\
\text { kain batik coklat Karakter } \\
\text { ini berperan sebagai Guide } \\
\text { Tour di dalam aplikasi dan } \\
\text { dalam animasi Tugu Jogja. }\end{array}$ \\
\hline 7. & 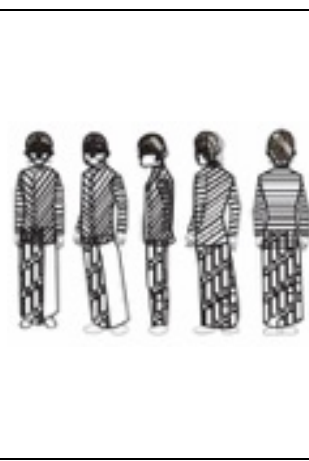 & $\begin{array}{l}\text { Nama Aset: Karakter } \\
\text { Title: 'Abdi Dalem } \\
\text { Keraton' } \\
\text { Deskripsi Aset: } \\
\text { Karakter Abdi Dalem } \\
\text { divisualisasikan memakai } \\
\text { bawahan batik coklat } \\
\text { Kawungan dan atasan motif } \\
\text { garis berwarna biru } \\
\text { selayaknya seragam/pakaian } \\
\text { Abdi Dalem secara nyata. } \\
\text { Karakter ini digunakan } \\
\text { dalam animasi Keraton } \\
\text { Yogyakarta. }\end{array}$ \\
\hline 8. & $\Rightarrow$ & $\begin{array}{l}\text { Nama Aset: Karakter } \\
\text { Title: 'Sultan } \\
\text { Hamengkubuwono VIII' } \\
\text { Deskripsi Aset: } \\
\text { Karakter Sultan HMB VIII } \\
\text { yang divisualisasikan sesuai } \\
\text { illustrasi foto Sultan berikut } \\
\text { ini: } \\
\text { Karakter ini digunakan } \\
\text { dalam animasi Keraton } \\
\text { Yogyakarta. }\end{array}$ \\
\hline 9. & 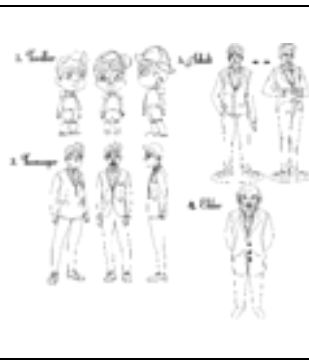 & $\begin{array}{l}\text { Nama Aset: Karakter } \\
\text { Title: 'Mas Tugu' } \\
\text { Deskripsi Aset: } \\
\text { Karakter ini divisualisasikan } \\
\text { sebagai seorang manusia } \\
\text { yang selalu tumbuh dan } \\
\text { berkembang dari balita } \\
\text { sampai tua. } \\
\text { Karakter ini digunakan } \\
\text { dalam animasi Tugu Jogja. }\end{array}$ \\
\hline
\end{tabular}




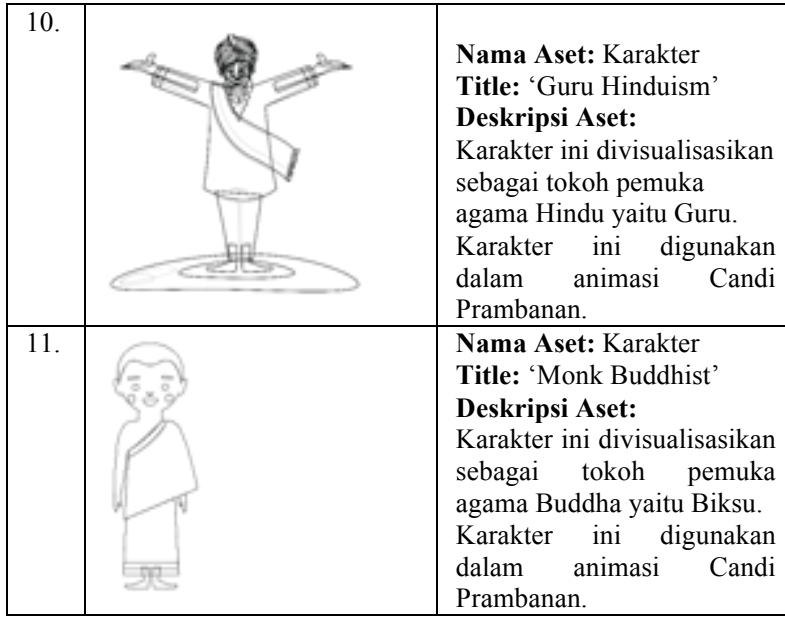

D. Desain Asset 3D

Desain aset-aset 3D dibuat untuk memudahkan dalam pembuatan aset-aset 3D pada media edukasi interaktif berdasarkan storyboard aplikasi virtual reality yang sudah dijabarkan sebelumnya. Desain aset 3D mempunyai beragam referensi gambar sebagai acuan untuk modelling, mulai dari sketsa gambar yang dibuat hingga foto serta denah asli monumen terkait. Pada Tabel 2 merupakan desain aset-aset 3D beserta penjelasannya.

TABEL. 2 DESAIN ASSET 3D

\begin{tabular}{|c|c|c|}
\hline No. & Desain Asset & Deskripsi \\
\hline 1. & inter & $\begin{array}{l}\text { Nama Aset: Keraton } \\
\text { Yogyakarta Front View } \\
\text { Deskripsi Aset: } \\
\text { Desain ini Penulis buat } \\
\text { sebagai referensi untuk } \\
\text { modelling 3D Keraton } \\
\text { Yogyakarta tampilan } \\
\text { depan. }\end{array}$ \\
\hline 2. & & $\begin{array}{l}\text { Nama Aset: Denah } \\
\text { Keraton } \\
\text { Deskripsi Aset: } \\
\text { Denah ini sebagai } \\
\text { referensi modelling 3D } \\
\text { Keraton Yogyakarta } \\
\text { tampilan atas dan } \\
\text { sekelilingnya. } \\
\text { Sumber: } \\
\text { www.google.com }\end{array}$ \\
\hline 3. & 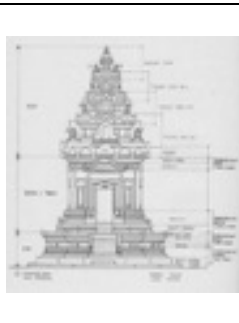 & $\begin{array}{l}\text { Nama Aset: Struktur } \\
\text { Relief Candi Prambanan } \\
\text { Deskripsi Aset: } \\
\text { Visualisasi struktur } \\
\text { bangunan Candi ini } \\
\text { sebagai referensi untuk } \\
\text { modelling 3D Candi } \\
\text { Prambanan. } \\
\text { Sumber: } \\
\text { www.google.com }\end{array}$ \\
\hline
\end{tabular}

\begin{tabular}{|c|c|c|}
\hline 4. & 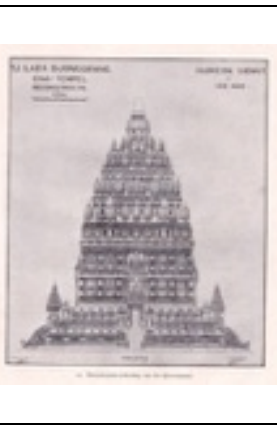 & $\begin{array}{lr}\text { Nama Aset: } & \text { Struktur } \\
\text { Relief Candi Prambanan } \\
2 \\
\text { Deskripsi Aset: } \\
\text { Visualisasi struktur } \\
\text { Candi ini sebagai } \\
\text { referensi tambahan untuk } \\
\text { menambahr detail } \\
\text { struktur relief modelling } \\
\text { 3D Candi Prambanan. } \\
\text { Sumber: } \\
\text { http://www.santijehanna } \\
\text { nda.com }\end{array}$ \\
\hline 5. & & 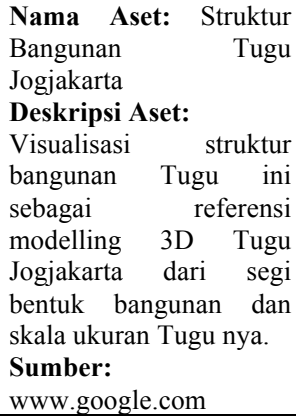 \\
\hline 6. & t & $\begin{array}{l}\text { Nama Aset: Struktur } \\
\text { Relief Tugu Jogjakarta } \\
\text { Deskripsi Aset: } \\
\text { Visualisasi Tugu ini } \\
\text { sebagai referensi } \\
\text { modelling 3D Tugu dari } \\
\text { segi detail ukiran dan } \\
\text { corak warna Tugu nya. }\end{array}$ \\
\hline
\end{tabular}

\section{E. Production}

Setelah perancangan desain aset 2D berdasarkan storyboard dan bahan material untuk media edukasi interaktif berbasis virtual reality telah selesai, selanjutnya tahap realisasi akan dilaksanakan. Tahap realisasi merupakan tahap Production pada metodologi Villamil-Molina. Pada tahap ini penulis mulai membuat realisasi desain user interface, karakter, dan objek 2D.

\section{1) Pembuatan Logo 'Victory'}

Dalam membuat suatu media edukasi interaktif berbasis virtual reality umumnya memiliki logo judul media edukasi tersebut, pembuatan logo "Victory" ini, diawali dengan membuat storyboard/sketsa yang akan diaplikasikan pada media edukasi. Sketsa dari logo judul "Victory" yang akan dibuat bentuk digitalnya terlihat pada Gambar 2.

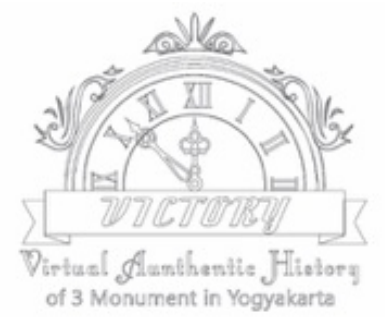

Gambar 2. Desain Logo 'Victory' 
Setelah membuat desain, dilakukan pembuatan bentuk visual digital dengan menggunakan perangkat lunak Adobe Illustrator. Desain ini akan di-import ke dalam halaman artboard perangkat lunak Adobe Illustrator sebagai cetak biru (blueprint) atau acuan untuk membentuk bentuk digitalnya.

Untuk membuat bentuk yang sesuai dengan gambar diperlukan tools yang terdapat dalam perangkat lunak ini. Penulis menggunakan Pen Tool untuk membuat bentuk jam tempo dulu dan ornamen di sekitar nya.

Selain itu juga digunakan Type Tool untuk membuat tulisan seperti pada desain logo. Pada logo ini Penulis menggunakan 2 tipe font yaitu Sans Serif dan Serif yang masing-masing font nya bernama 'Fontleroy Brown' dan 'Khmer UI'. Setelah itu desain logo dirapihkan dan diberi warna sehingga akan menghasilkan hasil akhir seperti Gambar 3.

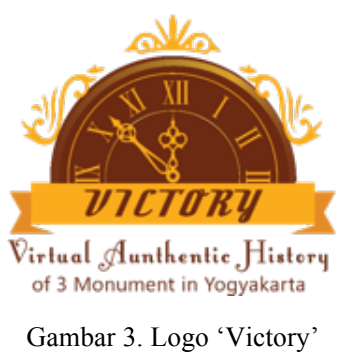

Elemen logo yang berbentuk jam tempo dulu secara keseluruhan merupakan representasi lambang mesin waktu dimana dalam aplikasi ini pengguna akan diajak menyusuri sejarah asal mula dibangunnya ketiga monumen terkait. Warna emas kuning yang nanti nya akan dipakai sebagai mayoritas warna logo diartikan sebagai aspek luhur dan prestis yang dikandung dalam konten-konten aplikasi yang kesemuanya diambil dari sumbersumber sejarah yang masih memegang adat istiadat dan budi luhur yang kuat.

\section{2) Pembuatan Desain User Interface}

Pembuatan desain user interface berdasarkan sketsa yang telah dibuat sebelumnya. Sketsa ini kemudian di-import ke dalam Adobe Illustrator. Kemudian tahap selanjutnya, dibuat bentuk yang sesuai dengan cetak biru dengan menggunakan Rectangle Tool, Ellipse Tool, dan Pen Tool.

Penulis juga di-import gambar yang diperlukan dari aset yang telah disiapkan, seperti background, objek dan logo, sehingga hasil akhir seperti terlihat pada Gambar 4.

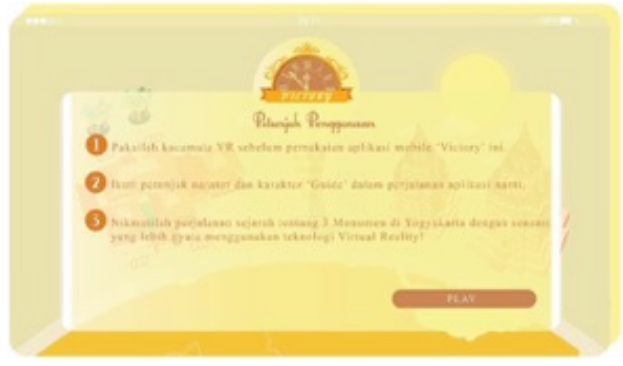

Gambar 4. User Interface Petunjuk Penggunaan Menu

Proses ini terus diulangi untuk membuat user interface lainnya sehingga seluruh storyboard/cetak biru menjadi gambar digital, kemudian menghasilkan suatu asset user interface yang utuh untuk aplikasi media edukasi interaktif ini.

\section{3) Pembuatan Karakter dan Background Animasi}

Pada pembuatan asset karakter animasi ini, juga digunakan gambar vektor untuk mencegah terjadinya blur atau pixelation saat penganimasian. Sama seperti sebelumnya juga, langkah pertama adalah melakukan digitalisasi dari gambar-gambar yang sudah didesain. Digitalisasi yang dimaksud adalah melakukan tracing dan coloring digital pada gambar manual. Proses dilakukan dengan Adobe Illustrator yang khusus digunakan untuk membuat gambar-gambar vektor.

Selain tracing dari hasil gambar/desain yang dibuat sendiri, digunakan juga foto atau gambar asli dari berbagai latar tempat untuk pembuatan background animasi. Hal ini dilakukan agar background tampak lebih nyata dan mempunyai kedekatan yang erat dengan objek realitas tempat aslinya seperti terlihat pada Gambar 5.

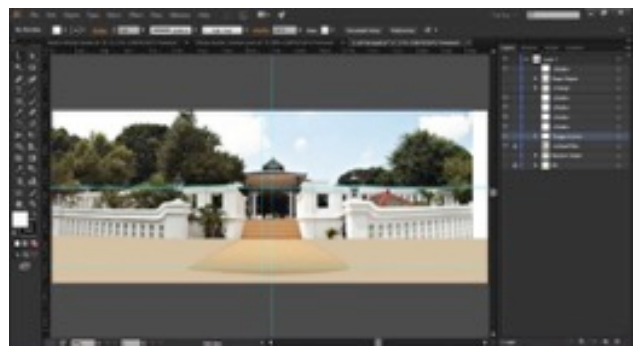

Gambar 5. Hasil Tracing dari Referensi Foto untuk Background Animasi

Di saat yang bersamaan coloring bisa langsung dilakukan dengan cara memilih warna yang lebih beraneka. Berikut adalah hasil dari tracing dan penggabungan beberapa stok vektor yang sudah dilakukan: 


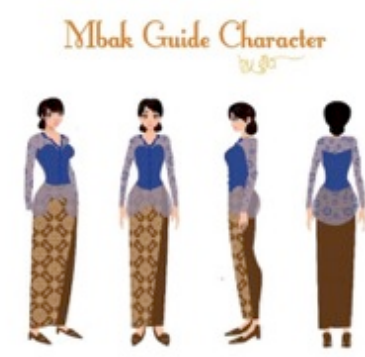

Gambar 6. Grafis Karakter 'Mbak Guide'

\section{4) Realisasi Desain Asset 3D}

Pembuatan modelling objek 3D ini, diawali dengan membuat storyboard/sketsa yang akan diaplikasikan pada layer Blender. Proses dilakukan dengan aplikasi Blender yang khusus digunakan untuk membuat modelling objek 3D. Desain dari Tugu Jogja yang akan dibuat bentuk digitalnya terlihat pada Gambar 7.

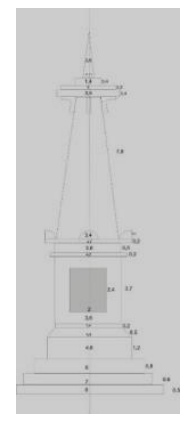

Gambar 7. Desain Tugu Yogyakarta

Langkah pertama yang dilakukan yaitu menambahkan background images sebagai referensi di layer Blender menggunakan Tab Properties dengan cara menekan shortcut $\mathrm{N}$ dan pilih Background Images pada bagian bawah dan masukkan sumber gambar nya dari file direktori.

Setelah background images dimasukkan, klik option Axis lalu pilih sudut pandang mana yang akan dibuat acuan dalam modelling nanti. Untuk ini, Penulis memilih axis sudut pandang kanan sebagai acuan gambar.

Setelah background dimasukkan kedalam layer Blender, maka buatlah modelling-nya menyerupai background images tsb. Penulis menggunakan mesh Cube dan curve path untuk membentuk objek badan Tugu.

Buat sebuah objek cube, lalu letakkan persis di lokasi background images. Skalakan objek cube tersebut sehingga ukuran cube seperti badan tugu pada background images. Gambar 8 adalah tampilan tugu menggunakan Mesh Cube.

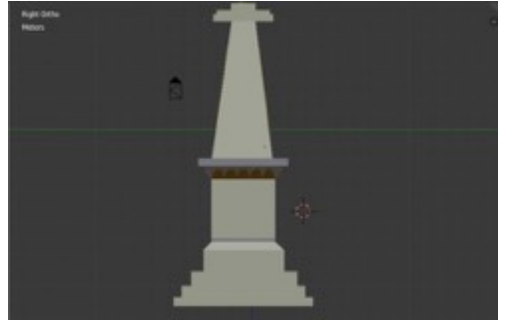

Gambar 8. Tampilan Objek Badan Tugu Menggunakan Mesh Cube

Setelah semua dibentuk menyerupai badan Tugu, maka selanjutnya adalah membuat modelling untuk ornamen-ornamen yang ada di objek. Dalam hal ini penulis menggunakan curve path untuk membuat ornament-ornamen tersebut agar memudahkan dalam membuat lengkunganlengkungan sudut objeknya.

Buat sebuah kurva Path, lalu putar arah sumbu Z sebesar 90 derajat sehingga bentuk kurva dapat sejajar dengan background images. Setelah itu bentuk kurva sesuai ornamen Tugu dengan cara menarik tuas sumbu sesuai dengan axis nya (X, Y, Z) di Edit Mode. Maka akan muncul sebuah objek kurva Path sesuai bentukan sumbu-sumbu kurva Path yang sudah dibentuk berdasarkan axis tersebut yang akan menyerupai garis luar ornamen Tugu.

Kurva Path yang sudah ada masih berupa kurva kosong tanpa volume. Oleh karena itu untuk memberi volume kurva sehingga menjadi objek menggunakan teknik Bevel Object di panel Geometri Properties dengan kurva Circle. Beberapa aset 2D dan 3D dapat dilihat pada Tabel 3.

TABEL 3. ASET 2D DAN 3D MONUMEN SEJARAH YOGYAKARTA

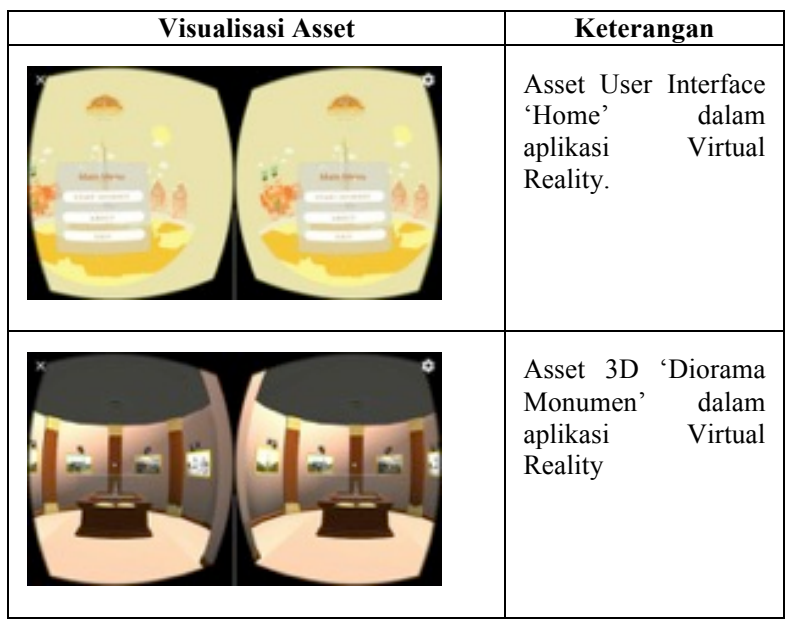




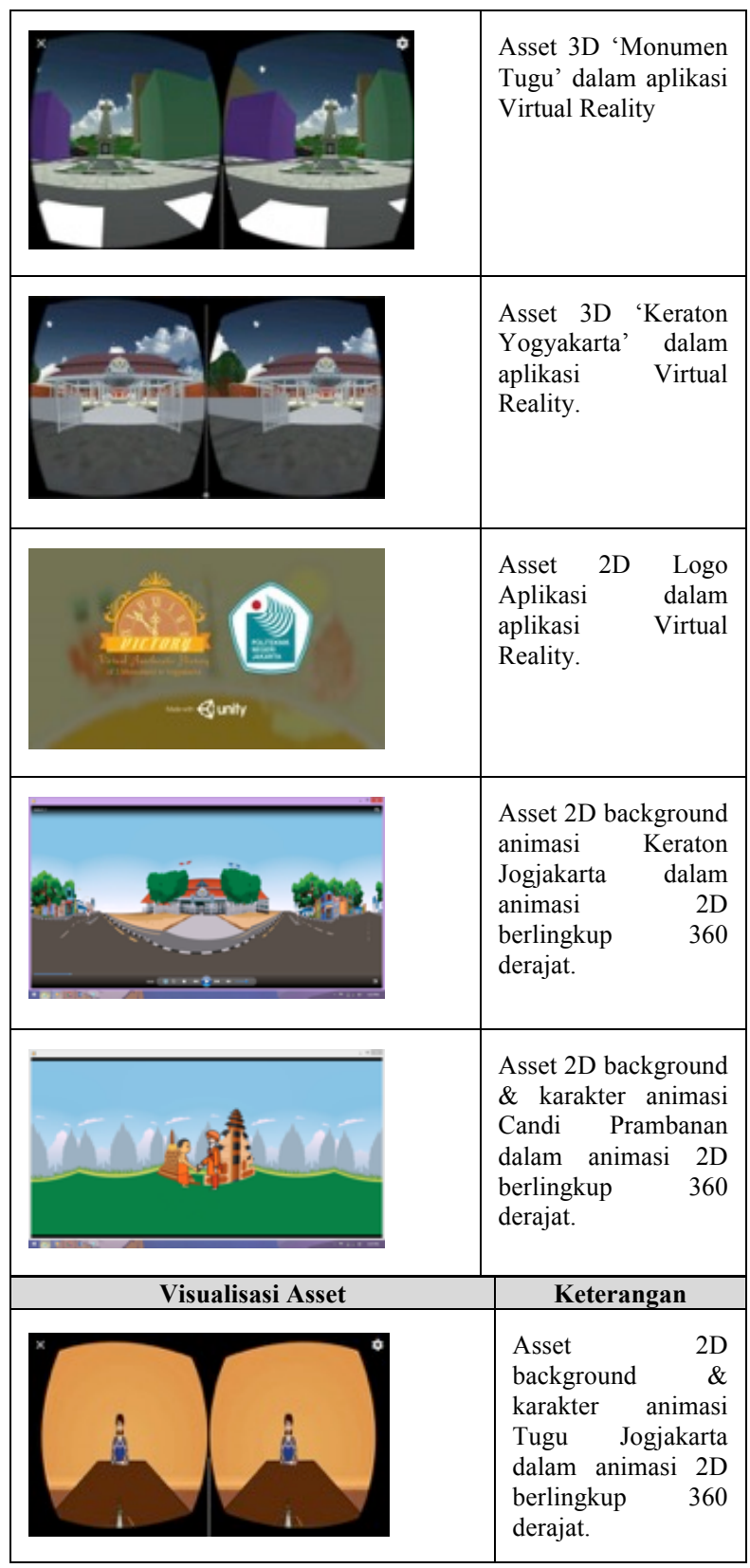

V. KESIMPULAN

Berdasarkan Pembuatan Asset Objek 2D \& 3D untuk Media Edukasi Interaktif Monumen Bersejarah DI Yogyakarta Berbasis Virtual Reality dapat disimpulkan bahwa:

1. Penelitian ini berhasil membuat asset 2D yang terdiri dari logo aplikasi, user interface aplikasi, karakter animasi dan background animasi, serta asset 3D yang terdiri dari monument objek dan ruang virtual pada media edukasi interaktif berbasis virtual reality.

2. Proses pembuatan desain user interface pada media edukasi interaktif berbasis virtual reality "Victory" dilakukan bertahap mulai dengan menentukan konsep, membuat desain, dan kemudian realisasi pembuatan desain user interface menggunakan perangkat lunak Adobe Illustrator CC 2015.

3. Desain user interface ini dibuat untuk memberikan tampilan media edukasi interaktif berbasis virtual reality yang mudah digunakan dan user friendly. User interface yang dibuat terdiri dari lima layout user interface, yaitu layout homescreen, instruction, menu about apps, menu about developer, dan menu exit.

\section{SARAN}

Adapun saran yang dapat disampaikan berdasarkan 2D dan 3D modelling monumen bersejarah DI Yogyakarta adalah :.

1. Pembuatan asset 2D pada media edukasi interaktif akan lebih baik jika dapat dibuat semenarik mungkin dengan lebih memperhatikan aspek warna dan ekspresi serta porsi tubuh sehingga para user lebih menikmati dan terhibur dalam menggunakannya.

2. Pembuatan asset 3D pada media edukasi interaktif sebaiknya dibuat secara mendetail dan se-ekploratif mungkin sehingga para user akan benar-benar merasa berada di suatu tempat dan dapat lebih bereksplorasi lebih jauh dengan objek 3D tersebut.

3. Pembuatan user interface akan lebih baik lagi jika dapat menerapkan seluruh prinsip perancangan user interface.

\section{REFERENSI}

[1] Anonim. Sejarah Singkat Provinsi Daerah Istimewa Yogyakarta. http://www.pendidikan-diy.go.id/ [23April 2015].

[2] Ardhianto. Eka, Hadikurniawati. Wiwien, Winarno, Edy. 2012. Augmented Reality Objek 3 Dimensi dengan Perangkat Artoolkit dan Blender. Program Studi Teknik Informatika. Universitas Stikubank.

[3] Lintau, Ephi. (2010). Perbedaan Grafik 3D dan 2D. http://ephi.web.id/ [20 Juli 2014]

[4] Sihite, B. 2013. Pembuatan Aplikasi 3D Viewer Mobile dengan Menggunakan Teknologi Virtual Reality. Jurnal Teknik Pomits 2(2) A397-A400.

[5] Binanto, Iwan. 2013. Perbandingan Metode Pengembangan Perangkat Lunak Multimedia. Teknik Informatika, Fakultas Sains dan Teknologi. Universitas Sanata Dharma. 